Article

\title{
Development and Physical Characterization of $\alpha$-Glucan Nanoparticles
}

\author{
Kervin O. Evans ${ }^{1, * \mathbb{C}}$, Christopher Skory ${ }^{1}$, David L. Compton ${ }^{1}{ }^{\mathbb{D}}$, Ryan Cormier ${ }^{1,+}$, \\ Gregory L. Côté ${ }^{1, \ddagger}$, Sanghoon Kim ${ }^{2}$ (D) and Michael Appell ${ }^{3}$ (D) \\ 1 Renewable Product Technology Research Unit, National Center for Agricultural Utilization Research, USDA, \\ 1815 N, University Street, Peoria, IL 61604, USA; Chris.Skory@usda.gov (C.S.); \\ David.Compton@usda.gov (D.L.C.); cormier.ryan@gmail.com (R.C.); cotegl@hotmail.com (G.L.C.) \\ 2 Plant Polymer Research Unit, National Center for Agricultural Utilization Research, USDA, 1815 N. \\ University Street, Peoria, IL 61604, USA; sanghoon.kim@usda.gov \\ 3 Mycotoxin Prevention and Applied Microbiology Research Unit, National Center for Agricultural \\ Utilization Research, USDA, 1815 N. University Street, Peoria, IL 61604, USA; michael.appell@usda.gov \\ * Correspondence: Kervin.Evans@usda.gov; Tel.: +1-309-681-6436; Fax: +1-309-681-6040 \\ + Current address: 1738 Citrus Hill Lane, Palm Harbor, FL 34683, USA. \\ $\ddagger$ Currently Retired.
}

Academic Editor: Derek J. McPhee

Received: 13 July 2020; Accepted: 19 August 2020; Published: 21 August 2020

\begin{abstract}
Glucans that were enzymatically synthesized from sucrose using glucansucrase cloned from Leuconostoc mesenteroides NRRL B-1118 were found to have a glass transition temperature of approximately $80{ }^{\circ} \mathrm{C}$. Using high-pressure homogenization $(\sim 70 \mathrm{MPa})$, the $\alpha$-glucans were converted into nanoparticles of $\sim 120 \mathrm{~nm}$ in diameter with a surface potential of $\sim-3 \mathrm{mV}$. Fluorescence measurements using 1,6-diphenyl-1,3,5-hexatriene (DPH) indicate that the $\alpha$-glucan nanoparticles have a hydrophobic core that remains intact from 10 to $85^{\circ} \mathrm{C}$. $\alpha$-Glucan nanoparticles were found to be stable for over 220 days and able to form at three $\mathrm{pH}$ levels. Accelerated exposure measurements demonstrated that the $\alpha$-glucan nanoparticles can endure exposure to elevated temperatures up to $60{ }^{\circ} \mathrm{C}$ for $6 \mathrm{~h}$ intervals.
\end{abstract}

Keywords: sucrose polysaccharide; biodegradable; nanoparticles; zeta potential; pH effect

\section{Introduction}

There is an ever-increasing drive to find biopolymers capable of forming nanoparticles. It is of special interest to find biopolymers that form nanoparticles capable of readily encapsulating hydrophobic bioactive agents because biopolymers tend to have better biocompatibility, better bioactivity, and/or lower toxicity than nanoparticles made from metals and/or synthetic polymers $[1,2]$. It is also important that the biopolymers suitable for making nanoparticles are biodegradable and come from a renewable source. Biodegradable biopolymers are likely to leave the least impact on the environment, and being from a renewable source means the ability to readily replenish the material.

$\alpha$-Glucans are polysaccharides with a repeating D-glucose monomer that can be produced enzymatically using glucansucrase, which catalyzes the transfer of $\alpha$-D-glucopyranosyl units from sucrose to acceptor molecules to form $\alpha$-glucan chains. These enzymes are synthesized by numerous lactic acid bacteria and can form several different $\alpha$-glucosidic linkages that affect the branching and water solubility of the polysaccharide. $\alpha$-glucans, such as dextran, contain mostly $\alpha(1 \rightarrow 6)$ linkages and are readily soluble in aqueous solvents. In contrast, $\alpha$-glucans that have a significant portion of $\alpha(1 \rightarrow 3)$ linkages often form extended ribbon-like helices, rendering the biopolymers insoluble [3-5]. Thus, the $\alpha$-glucan polysaccharides studied in this work are natural, biodegradable, and highly renewable materials for making nanoparticles. 
Water-insoluble glucans, which are produced by several species of Streptococcus and Leuconostoc bacteria [6-12], usually have a mixture of both linkage types, imparting an amphipathic characteristic to the polysaccharide that can be used to create novel nanoparticles. We previously showed that high-pressure homogenization (10-60 passes at 35 to $200 \mathrm{MPa}$ ) of water-insoluble glucans could be used to form nanoparticles with the potential for encapsulation or film formation. We showed that several different water-insoluble glucans could be used to form nanoparticles with varying size and polydispersity. Polysaccharide produced from a cloned glucansucrase from Leuconostoc mesenteroides NRRL B-1118 typically yielded the most reproducible nanoparticles with a diameter less than $200 \mathrm{~nm}$. Physical characterization of these nanoparticles, such as surface charge or stability, has been limited. This work explores the thermal properties of $\alpha$-glucans that are not nanoparticles, the stability of the $\alpha$-glucan nanoparticles over a temperature range of $10^{\circ} \mathrm{C}$ to $86^{\circ} \mathrm{C}$ using fluorescence anisotropy, and the nanoparticles' size and zeta potential over a 7-month period and under accelerated exposure at $23{ }^{\circ} \mathrm{C}, 37^{\circ} \mathrm{C}$, and $60{ }^{\circ} \mathrm{C}$.

\section{Results and Discussion}

\subsection{DSC Analysis}

Thermal properties of the $\alpha$-glucan polysaccharides were investigated using DSC measurements because heat gain and loss may be accompanied by structural changes within the polysaccharide.

Figure 1 shows the result of the thermal analysis of pure $\alpha$-glucan polysaccharides prior to their formation into nanoparticles. Indications are that the native $\alpha$-glucan polysaccharides exhibited a small endothermic peak near $70{ }^{\circ} \mathrm{C}$. This is interpreted as the transition temperature for the start of structural changes in the $\alpha$-glucans. The data suggest that structural unwinding is completed at approximately $80^{\circ} \mathrm{C}$, which may be the degradation temperature where nanoparticles made from these glucans completely unravel. It should be noted that a similar temperature range was found for exopolysaccharides produced from Lactobacillus plantarum KF5 isolated from Tibet kefir grains [13] but is well below the melting temperature characteristic of levan synthesized by levansucrase.

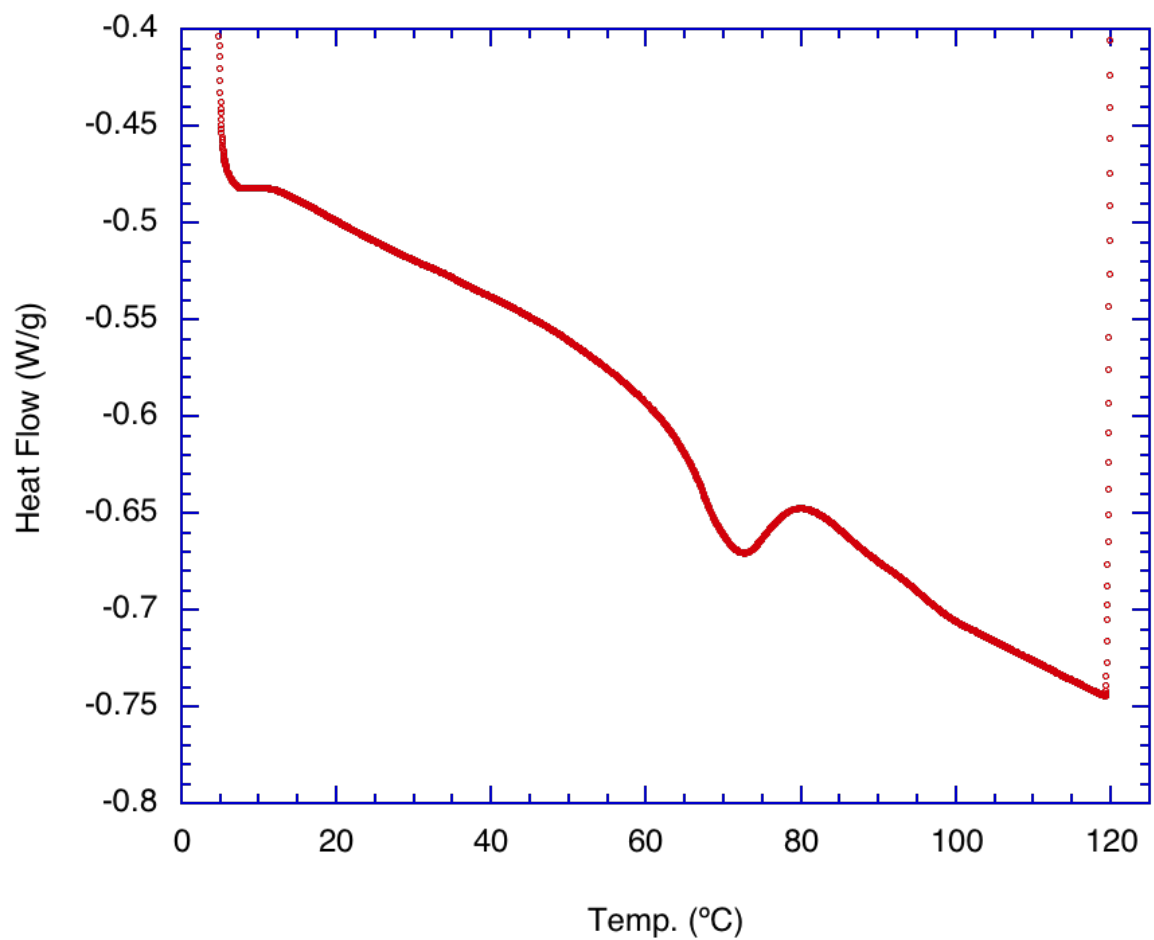

Figure 1. Differential scanning calorimetry (DSC) thermal analysis of purified, freeze-dried alpha glucan synthesized from Leuconostoc mesenteroides NRRL B-1118 glucansucrase. 
Further thermal analysis was conducted on $\alpha$-glucan polysaccharides, prior to their being made into nanoparticles, by exploring TGA measurements; Figure 2 shows the results. Degradation for the $\alpha$-glucan polysaccharides occurred in two stages. The first stage of weight loss, which occurred from $25^{\circ} \mathrm{C}$ to about $100{ }^{\circ} \mathrm{C}$, was similar to that found for chitosan [14] and accounted for approximately $9.2 \%$ of mass contents. This was likely due to the loss of weight from adsorbed water being evaporated. The second stage did not start until the temperature was $\sim 160{ }^{\circ} \mathrm{C}$ and continued to $\sim 340{ }^{\circ} \mathrm{C}$, where $18-19 \%$ mass remained, which was likely due to the thermal breakdown of the $\alpha$-glucan polysaccharides. Differential TGA shows that $50 \%$ of the $\alpha$-glucan polysaccharides' mass degraded at around $320{ }^{\circ} \mathrm{C}$. The TGA data confirm that the lower transition temperature presented by DSC measurements is associated with structural changes in the glucan since the mass loss associated with polysaccharide degradation did not occur prior to about $160^{\circ} \mathrm{C}$.

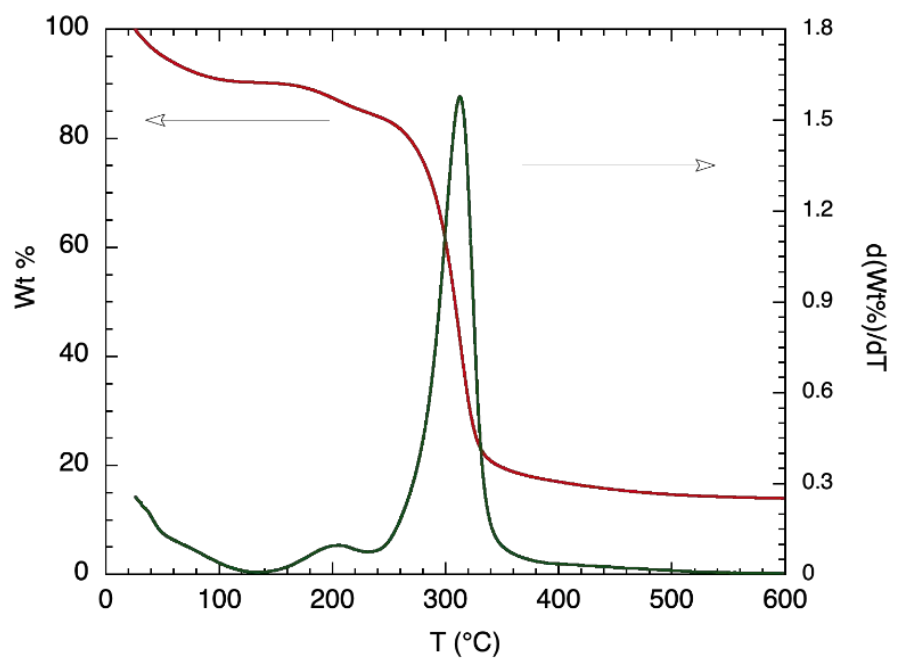

Figure 2. TGA (red line; left y-axis) and differential TGA (green line; right y-axis) thermogram of purified alpha-glucan polysaccharide glucansucrase.

Figure 3a shows the water-insoluble glucan dispersed in water before and after homogenization. The mixture was cloudy prior to homogenization and readily reached clarity after homogenization. It was determined that approximately $70 \mathrm{MPa}$ and 60 passes were the conditions necessary to optimize nanoparticle size (Figure 3b). Optimized conditions resulted in nanoparticles in the size range of 108 to $128 \mathrm{~nm}$ in diameter.

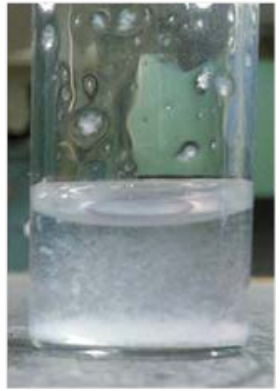

Water-Insoluble Glucan in Water

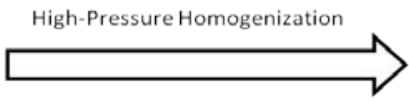

$10-60$ Passes at 35 to $200 \mathrm{MPa}$

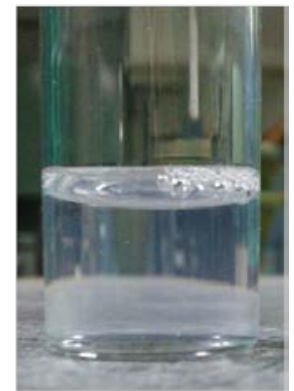

Glucan

Nanospheres in Water

(a)

Figure 3. Cont. 


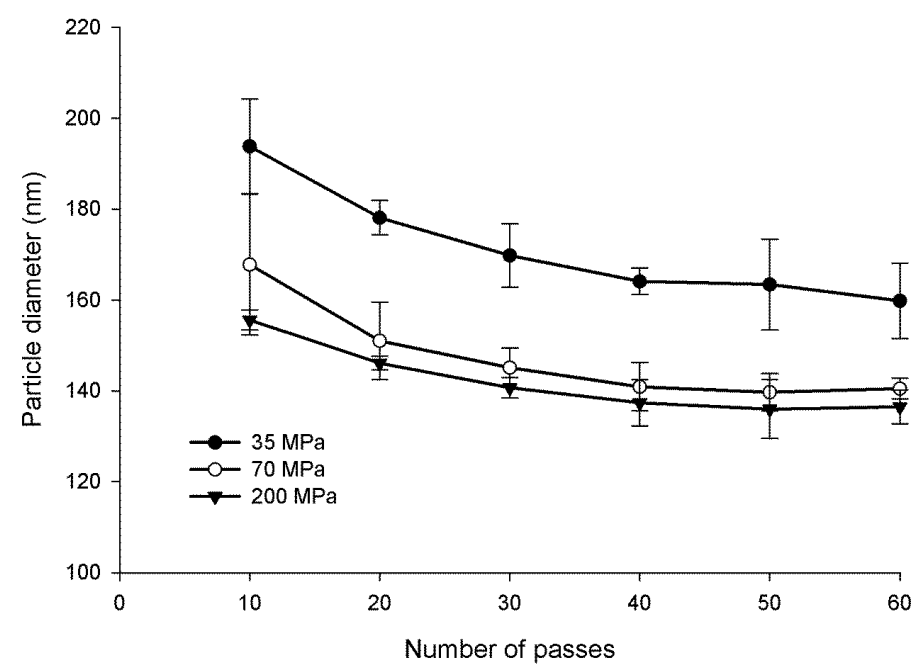

(b)

Figure 3. $\alpha$-Glucans were homogenized in water to clarity to form nanoparticles (a). Nanoparticle size as a function of pressure and passes through homogenization (b).

\subsection{Morphology Analysis of $\alpha$-Glucans and Nanoparticles}

Figure $4 \mathrm{~A}$ shows the results of SEM images of freshly prepared $\alpha$-glucan that had been extensively rinsed with water and air-dried. Air-drying resulted in a non-uniform distribution of the polysaccharide and the appearance of apparently agglomerated spheres. Figure 4B shows the results of the air-dried samples after freeze-drying at $-20^{\circ} \mathrm{C}$. It is shown that the agglomerated spheres disappeared and were replaced by a fibrous network of the polysaccharide. Figure $4 \mathrm{C}$ shows that the freeze-dried polysaccharides assembled into spherical nanospheres after homogenization and were similar in size to that determined by DLS measurements.
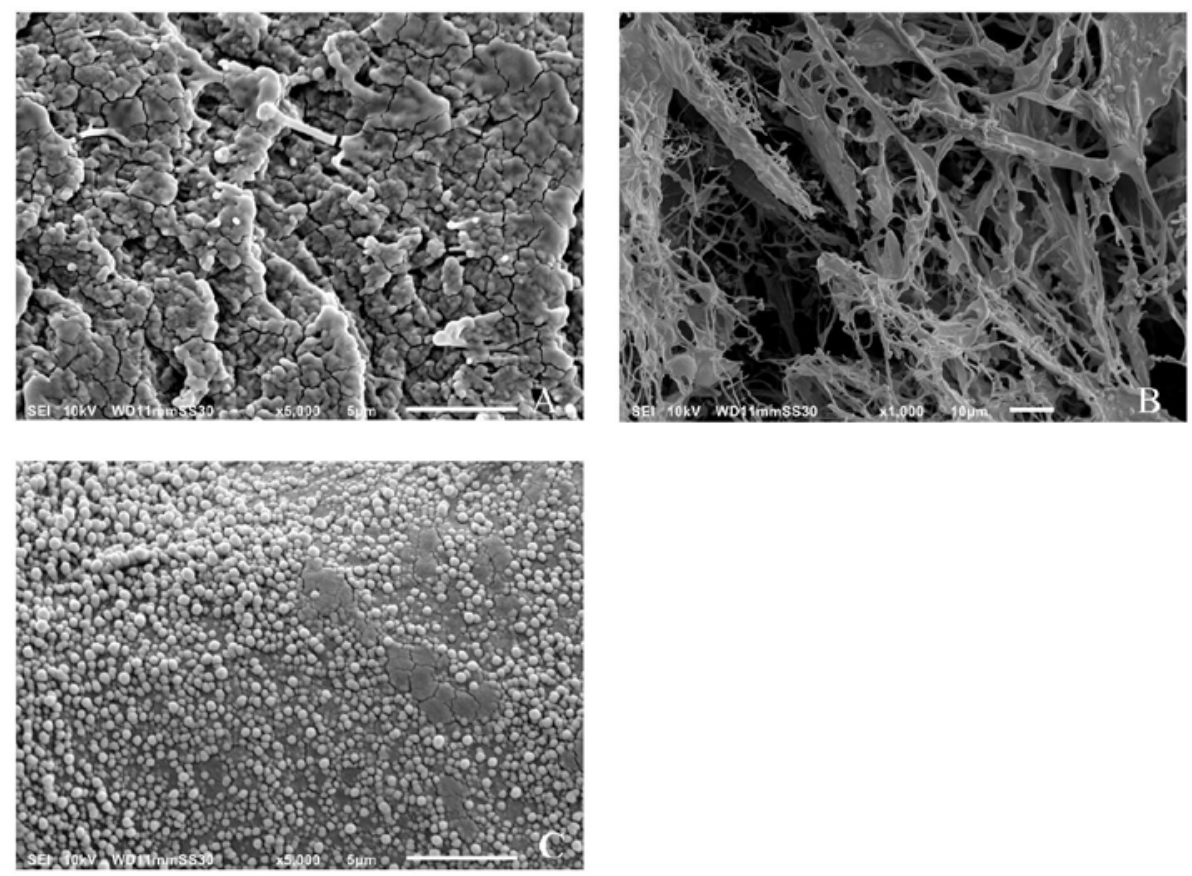

Figure 4. Scanning electron micrograph images of air-dried (A), freeze-dried (B), and freeze-dried/ homogenized (C) $\alpha$-glucans. 
It is believed that nanoparticle formation can be partially attributed to the nature of the $\alpha-(1 \rightarrow 3)$-linked and $\alpha-(1 \rightarrow 6)$-linked D-glucose units in the polysaccharide. Previous work done on a similar glucan produced by Streptococcal mutans described the branched $\alpha-(1 \rightarrow 6)$-linked portion of the biopolymer as being responsible for its adherence to the hydrophilic hydroxylapatite in teeth $[4,5]$. High-pressure homogenization of the $\alpha$-glucan could force the rigid $\alpha-(1 \rightarrow 3)$-linked regions responsible for its insolubility into the center of a forming sphere while forcing the $\alpha-(1 \rightarrow 6)$-linked regions to the surface to maximize the hydrophilic interaction with the aqueous media.

\subsection{Fluorescence Anisotropy Analysis}

The hydrophobicity of the $\alpha$-glucans makes them insoluble in water. Detecting hydrophobicity in glucans after they are converted to nanoparticles is possible using the fluorescent probe DPH because DPH preferentially intercalates into hydrophobic regions in the aqueous environments where it is quenched [15]. The addition of DPH to formed nanoparticles resulted in the typical emission spectrum of DPH inside a hydrophobic environment $[15,16]$, indicating that polarization and subsequently anisotropy were measurable. Anisotropy measurements are based on the ability of a fluorescent probe molecule to rotate about its environment and on detecting the difference between the horizontal and vertical components of the probe's fluorescence emission signal during this rotation [17]. The more the probe molecule rotates, the smaller the difference becomes between the vertical and horizontal components of the emitted light. Figure 5 shows the anisotropy of DPH, from $10-86{ }^{\circ} \mathrm{C}$, when DPH is intercalated into $\alpha$-glucan nanoparticles. DPH anisotropy with the nanoparticles exhibited its highest value ( 0.625) from 10 to $18^{\circ} \mathrm{C}$, indicating the least rotational freedom of DPH. This suggests that molecular packing is tightest within the nanoparticles at $10-18{ }^{\circ} \mathrm{C}$. Molecular packing within the nanoparticles decreased over the temperature range of 18 to $54{ }^{\circ} \mathrm{C}$. Unexpectedly, the anisotropy started to increase above $55^{\circ} \mathrm{C}$ and returned to near the previous level seen at $10-18{ }^{\circ} \mathrm{C}$. This indicates that molecular packing increased and subsequently returned to previous levels, suggesting that the endothermic peak seen in Figure 1 is a transition temperature for the $\alpha$-glucans, where the polysaccharide possibly unfolded. The fact that the anisotropy at $86^{\circ} \mathrm{C}$ was about the same value as it was at $10{ }^{\circ} \mathrm{C}$ indicates that a significant population of nanoparticles did not fully unravel at high temperatures, suggesting that the nanoparticles are highly stable and resistant to temperature degradation up to nearly $90{ }^{\circ} \mathrm{C}$. Additionally, the fact that DPH, which has a higher affinity for hydrophobic regions, was measurable fluorescently within these nanoparticles during the entire temperature range from $10{ }^{\circ} \mathrm{C}$ to $86^{\circ} \mathrm{C}$ suggests that other hydrophobic bioactives will associate within the nanoparticles over the same temperature range (thus, binding kinetics and controlled-release studies will be studied over this temperature range in later work).

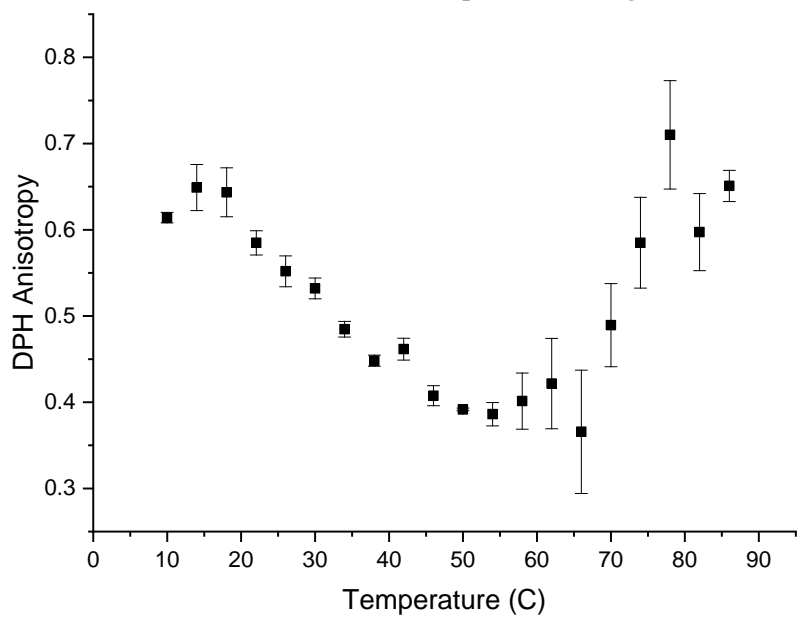

Figure 5. Anisotropy measurement of 1-6-diphenyl-1,3,5-hextriene (DPH) that was intercalated into $\alpha$-glucan nanoparticles. 


\subsection{DLS and $\zeta-P o t e n t i a l$ Analysis}

Considering that the $\alpha$-glucans homogenized into nanoparticles (Figure 3 ), it is important to characterize the stability of the nanoparticles. This was done by monitoring their size and zeta-potential over several days. DLS results (Figure 6) show that the $\alpha$-glucan nanoparticle had a mean diameter of approximately $118 \mathrm{~nm}$ after homogenization and increased in size to nearly $122 \mathrm{~nm}$ in about 225 days. The error bars indicate little difference in the nanoparticle sizes during this time; however, ANOVA analysis shows that, overall, there was a significant difference $(p<0.5)$, suggesting that the nanoparticles are so stable that their size changed only slightly during the 7 months and that they do not aggregate. It should be noted that the filtration of the $\alpha$-glucan nanoparticles using a 0.45 -micron filter to remove any unusually large nanoparticles did not change the mean diameter (data not shown). Zeta potential measurements show that the nanoparticles had a low zeta potential $(\sim-5 \mathrm{mV})$ and that it was relatively constant over the same 225 days. Typically, colloidal systems are considered highly stable when they have zeta potential at or above $\pm 30 \mathrm{mV}$, which is where nanoparticles are less likely to aggregate [18]. The size stability here suggests that despite the low zeta potential, the $\alpha$-glucan nanoparticles produced by homogenization did not aggregate and were quite stable. This is similar to the findings for similar surfactant-free nanoparticles made from enzymatically synthesized inulin [19].

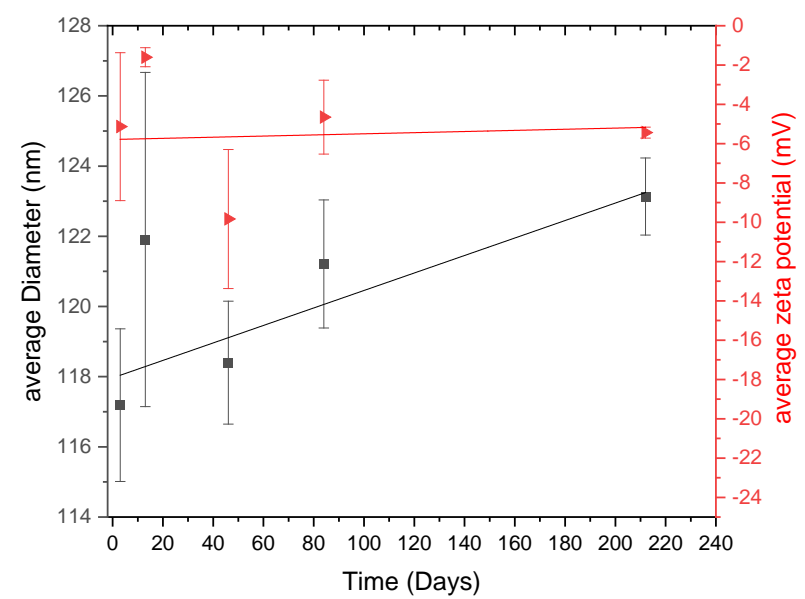

(a)

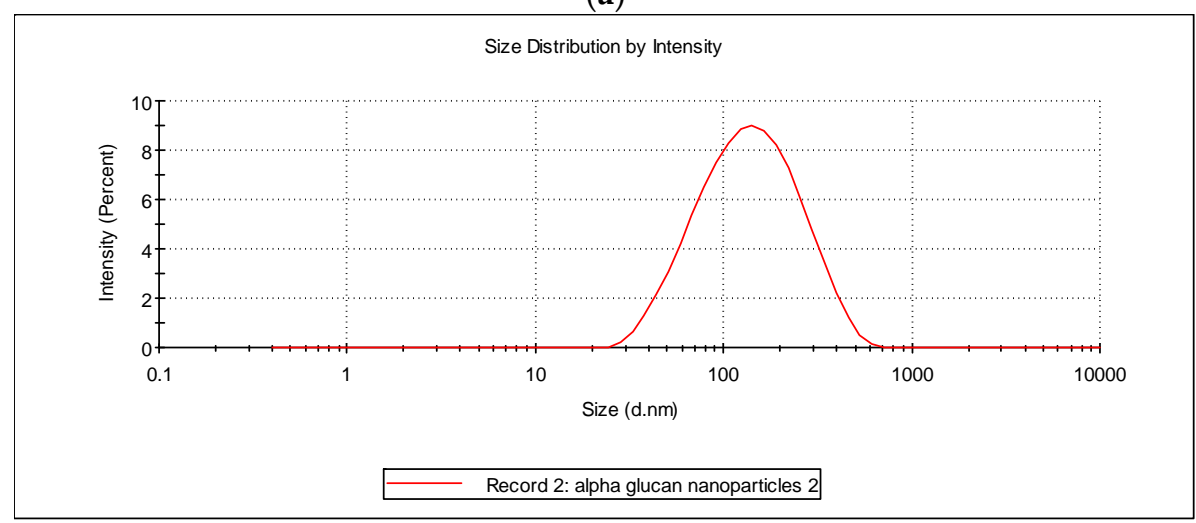

(b)

Figure 6. (a) Diameter and zeta potential of $\alpha$-glucan nanoparticles monitored over time; (b) representative graph of size distribution of $\alpha$-glucan nanoparticles during size measurements.

It is also important to monitor the stability of nanoparticles as a function of pH levels [20-22]. Figure 7 shows the size and zeta potential results for nanoparticles created at three different $\mathrm{pH}$ levels ( $\mathrm{pH}$ 5.5, 7.4, and 10). Buffering agents MES, TES, and CHES were used to maintain the respective $\mathrm{pH}$ levels of $5.5,7.4$, and 10 of the nanopore water in which the $\alpha$-glucans were hydrated. $\alpha$-Glucans 
homogenized to form nanoparticles at pH 5.5 had a mean hydrodynamic diameter of nearly $120 \mathrm{~nm}$; those nanoparticles that formed at $\mathrm{pH} 7.4$ were slightly larger, approximately $122 \mathrm{~nm}$ in diameter. $\alpha$-Glucan nanoparticles that formed at $\mathrm{pH} 10$, however, had a mean diameter of approximately $115 \mathrm{~nm}$. Statistical analysis using a one-way ANOVA test showed that these sizes were significantly different. The different sizes of $\alpha$-glucan nanoparticles suggest that nanoparticles created under acidic and neutral conditions are an optimal size, and those made under basic conditions will obtain their smallest size. Analysis of the zeta potential of the $\alpha$-glucan nanoparticles under different $\mathrm{pH}$ conditions exhibited a decreasing trend in the presence of sulfonic acid buffering agents $(-0.3 \mathrm{mV}$ under acidic conditions, nearly $-0.8 \mathrm{mV}$ at neutral conditions, and approximately $-1.3 \mathrm{mV}$ under basic conditions). It should be noted that without a buffering agent present, the $\alpha$-glucan nanoparticles had a zeta potential in the range of -3 to $-8 \mathrm{mV}$. This suggests that buffering agents of different chemical structures may influence the surface charge of the nanoparticles, possibly by a shielding effect. This is to be further evaluated in later studies.

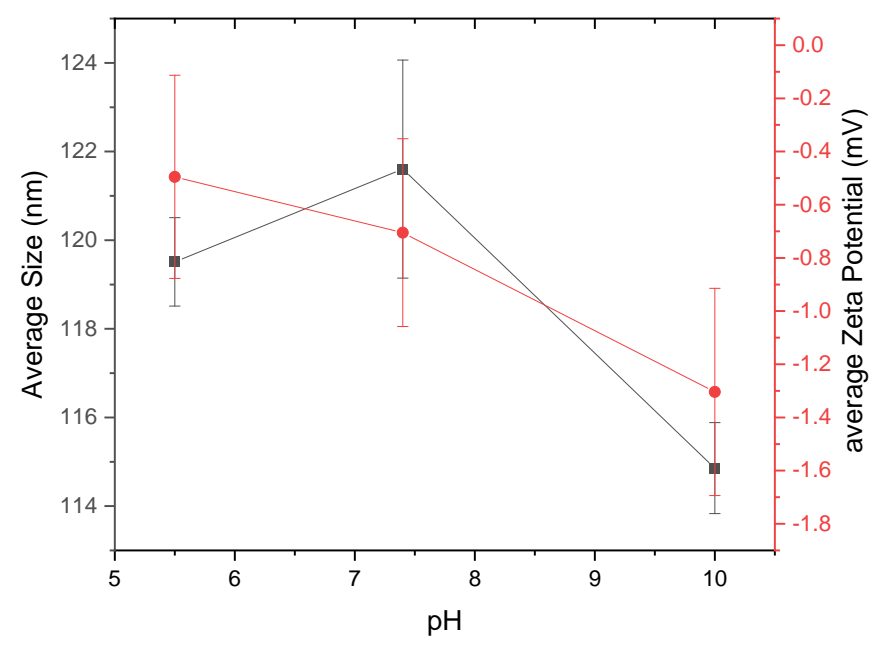

Figure 7. $\alpha$-Glucan nanoparticles size (black square) and zeta potential (red circle) as a function of $\mathrm{pH}$.

It is also important to understand the stability of the $\alpha$-glucan nanoparticles under various temperature conditions. Therefore, accelerated exposure was conducted to determine how varied temperatures affected the nanoparticles. Nanoparticles were exposed to $25^{\circ} \mathrm{C}$ (ambient temperature), $37^{\circ} \mathrm{C}$ (body temperature), and $60^{\circ} \mathrm{C}$ (high temperature) for $5 \frac{1}{2} \mathrm{~h}$ intervals, consecutively. Figure 8 shows that exposure to a temperature of $25^{\circ} \mathrm{C}$ resulted in the nanoparticle size being relatively unchanged for $8 \mathrm{~h}$; however, the zeta potential linearly decreased to $-26 \mathrm{mV}$, and it is unclear why this was the case. Two hours into the second time interval, where the temperature was $37^{\circ} \mathrm{C}$, the nanoparticles exhibited an exponential increase in average diameter, reaching approximately $119 \mathrm{~nm}$. The nanoparticles exhibited their maximum negative zeta potential of approximately $-55 \mathrm{mV}$, which increased linearly to about $-47 \mathrm{mV}$. Increasing the temperature to $60^{\circ} \mathrm{C}$ resulted in the nanoparticles rapidly returning to $108 \mathrm{~nm}$ diameter and increasing to approximately $119 \mathrm{~nm}$ in diameter over the first half an hour at $60{ }^{\circ} \mathrm{C}$. The nanoparticles then returned to $108 \mathrm{~nm}$ in size over the second $30 \mathrm{~min}$ period at $60{ }^{\circ} \mathrm{C}$, only to increase in size to $119 \mathrm{~nm}$ over the final hour at $60^{\circ} \mathrm{C}$. The zeta potential, on the other hand, appears to stabilize at approximately $-39 \mathrm{mV}$ during the entire duration of the nanoparticles being heated at $60{ }^{\circ} \mathrm{C}$. Finally, returning the temperature to $25^{\circ} \mathrm{C}$ resulted in apparently immediate shrinkage of the nanoparticles to approximately $99 \mathrm{~nm}$ in size. The nanoparticles returned to $108 \mathrm{~nm}$ in size over the $30 \mathrm{~min}$ period it took for the temperature to equilibrate to $25^{\circ} \mathrm{C}$. The zeta potential, during the $30 \mathrm{~min}$ that the temperature was gradually lowered back to $25^{\circ} \mathrm{C}$, decreased to approximately $-65 \mathrm{mV}$ and returned to $-39 \mathrm{mV}$ once $25^{\circ} \mathrm{C}$ was achieved. 


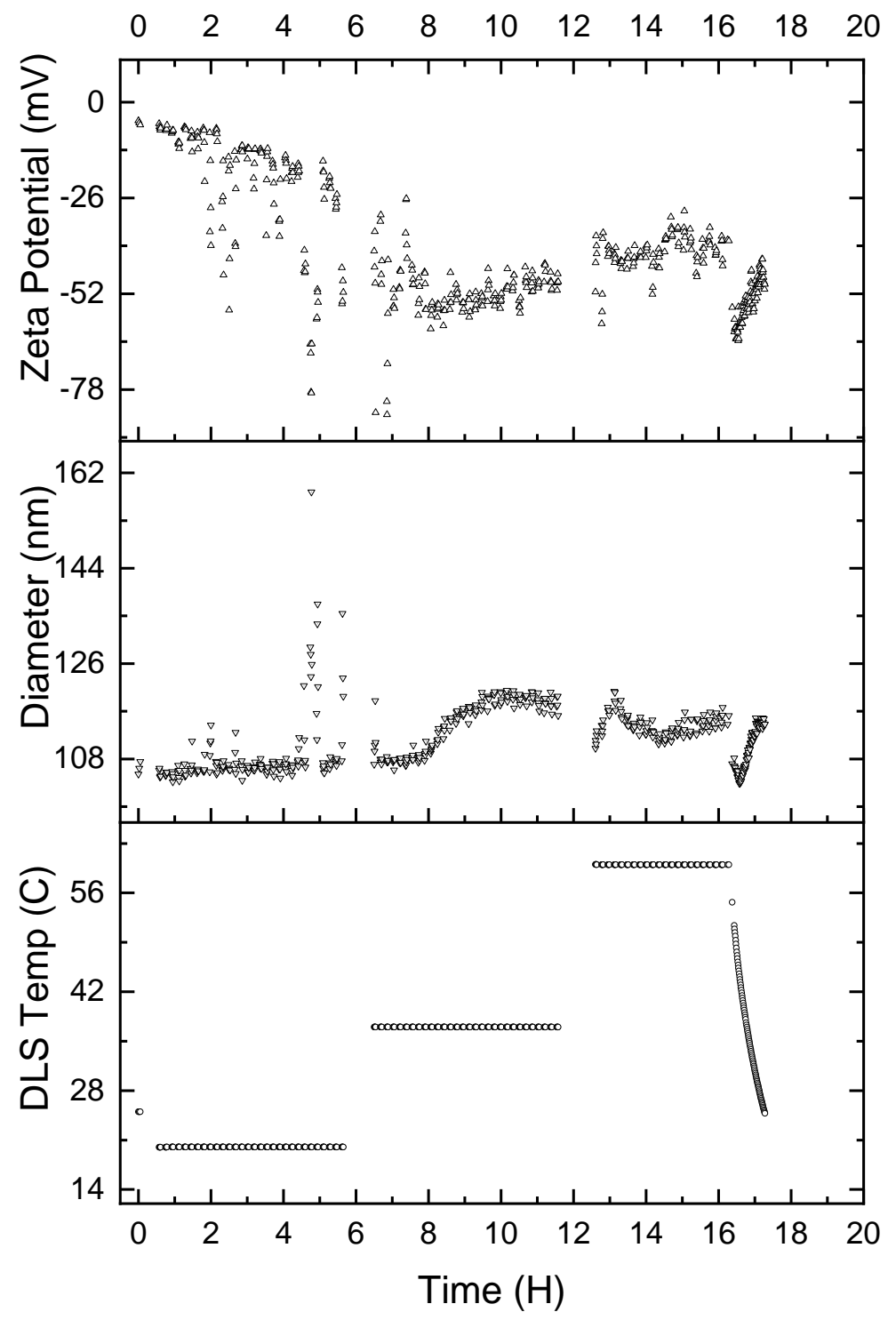

Figure 8. Accelerated exposure of $\alpha$-glucan nanoparticles for $5 \frac{1}{2} \mathrm{~h}$ intervals at 25,37 , and $60{ }^{\circ} \mathrm{C}$, respectively; temperature conditions were gradually returned to $25^{\circ} \mathrm{C}$ after $16 \mathrm{~h}$.

\section{Materials and Methods}

\subsection{Materials}

The high-pressure homogenizer, model C5, was purchased from Avestin, Inc. (Ottawa, ON, Canada). 1,6-Diphenyl-1,3,5-hexatriene (DPH) was purchased from ThermoFisher Scientific (St. Louis, MO, USA). Buffering agents 2-( $N$-morpholino)ethanesulfonic acid (MES), 2-[[1,3-dihydroxy-2(hydroxymethyl)propan-2-yl]amino]ethanesulfonic acid (TES), and 2-(cyclohexylamino)ethanesulfonic acid (CHES) were purchased from Sigma-Aldrich (St. Louis, MO, USA) at chemical grade. A Barnstead NANOpure Diamond UV ultrapure water purification system with a resistivity of $18.2 \mathrm{M} \Omega \mathrm{cm}$ was the source of the water used throughout this work. 


\subsection{Methods}

\subsection{1. $\alpha$-Glucan Synthesis and Structural Characterization}

Synthesis and structural characterization of the $\alpha$-glucan used in this work was carried out previously by Côté and Skory, 2012 [23]. Briefly, the insoluble $\alpha$-glucans were synthesized using a glucansucrase cloned from the NRRL B-1118 (ATCC 8293) strain of Leuconostoc mesenteroides, a lactic acid bacterium, and structurally analyzed using hydrolysis, gas-liquid chromatography, and methylation. Together, these analyses indicated that the glucans had nearly equal proportions of $\alpha-(1 \rightarrow 3)$ and $\alpha-(1 \rightarrow 6)$ linkages; branching was indicated to have minimally occurred. The final polysaccharide product was freeze-dried and stored until usage.

\subsubsection{Differential Scanning Calorimetry (DSC)}

Experiments using DSC were explored to ascertain the thermal properties of the $\alpha$-glucans prior to their formation as nanoparticles. Experiments were conducted in a TA Instruments Q2000 MDSC (TA Instruments, Inc., New Castle, DE, USA). Samples were weighed ( $\sim 3 \mathrm{mg}$ ) and sealed under nitrogen in a hermetic aluminum DSC pan; an empty pan sealed under nitrogen was used as the reference. Samples were equilibrated to $4^{\circ} \mathrm{C}$ and heated to $120^{\circ} \mathrm{C}$ at a heating rate of $5^{\circ} \mathrm{C} / \mathrm{min}$.

\subsubsection{Thermogravimetric Analysis (TGA)}

Further thermal analysis was conducted by obtaining TGA thermograms using a Q500 TGA instrument (TA Instruments, New Castle, DE, USA). Samples $(\sim 10 \mathrm{mg})$ were placed onto a tared, open platinum TGA pan and heated from room temperature $\left(20-25^{\circ} \mathrm{C}\right)$ up to $600{ }^{\circ} \mathrm{C}$. This was done under nitrogen and at a rate of $5{ }^{\circ} \mathrm{C} / \mathrm{min}$. Additional to measuring weight loss, differential TGA weight loss $\left(\mathrm{DTG}, \% /{ }^{\circ} \mathrm{C}\right)$ was also recorded; measurements were conducted in duplicate.

\subsubsection{Nanoparticle Preparation via High-Pressure Homogenization}

Dried water-insoluble glucan was added to room-temperature water $(40 \mathrm{~mL})$ to give a weight-to-volume $(w / v)$ solution with up to $5 \%$ solid content (maximum material passable through the homogenizer). A concentration of $0.25 \% w / v(100 \mathrm{mg})$ was chosen for these experiments and mixed overnight for approximately $18 \mathrm{~h}$ to maximize dispersion and hydration. Using an Avestin Emulsiflex-C5 high-pressure homogenizer, the dispersed water-insoluble glucans were homogenized at approximately $70 \mathrm{MPa}$ and continuously passed through the homogenizer 60 times until a clear solution was achieved (conditions determined from evaluating pressures of 35, 70, and $200 \mathrm{MPa}$ and 10-60 passes; see Figure 3b) [24].

\subsubsection{Morphological Analysis}

The shape of the nanoparticles was determined via scanning electron microscopy (SEM) utilizing a JEOL JSM-6010A (JEOL USA, Inc., Peabody, MA, USA,). All samples were dried, adhered to aluminum specimen mounts by conductive carbon tape, and then sputter-coated with gold.

\subsubsection{Fluorescence Anisotropy Measurements}

Hydrophobic properties and possible temperature phase transition points of the $\alpha$-glucan nanoparticles were explored using the fluorescent properties of 1,6-diphenyl-1,3,5-hexatriene (DPH). DPH is well known for partitioning into the hydrophobic region of phospholipid membranes, where the fluorescence of DPH is unquenched compared to DPH residing within water and is used to monitor temperature-induced phase transitions within the lipid bilayer $[15,16]$. A similar study was undertaken with formed nanoparticles, first to confirm the existence of an internal hydrophobic region (vital for nanoparticles to remain in aqueous solution without separation) and, second, to explore whether the nanoparticles exhibited any detectable temperature-induced phase transitions. DPH in 
methanol was added to preformed nanoparticles in water; the DPH final concentration in solution was $1 \mu \mathrm{M}$. Nanoparticles with DPH were incubated with periodic shaking for 30 min to maximize $\mathrm{DPH}$ partitioning into the hydrophobic region of the nanoparticles. DPH/nanoparticle samples were placed into cuvettes and equilibrated to $4{ }^{\circ} \mathrm{C}$. Excitation and emission wavelengths were set to $350 \mathrm{~nm}$ and $428 \mathrm{~nm}$, respectively, on a Horiba Jobin-Yvon Fluorlog 3-21 fluorometer (Piscataway, NJ, USA). Anisotropy measurements were conducted from $4{ }^{\circ} \mathrm{C}$ to $80^{\circ} \mathrm{C}$ at 4-degree intervals; samples were equilibrated at each temperature for $10 \mathrm{~min}$ prior to measurements being made, and the sample chamber was purged with pure nitrogen during the entire experiment to eliminate condensation on the cuvettes. Anisotropy was calculated as reported in Evans and Compton, 2017 [5]; the correction factor $\mathrm{G}$ was determined by using nanoparticles without DPH but incubated 30 min with the appropriate amount of methanol. Experiments were conducted in triplicate.

\subsubsection{Dynamic Light Scattering (DLS) and Zeta Potential Measurements}

The size and zeta potential of the nanoparticles were determined using DLS and electrophoresis, respectively, from a Zetasizer Nano-ZS (Malvern, UK) that used $633 \mathrm{~nm}, 4 \mathrm{~mW}$ He-Ne red laser. Measurements were conducted at $25^{\circ} \mathrm{C}$ using a $173^{\circ}$ detection angle. One measurement entailed up to 13 runs, each lasting up to $20 \mathrm{~s}$ per run; 3 runs were conducted per sample. Data were averaged to obtain average particle size and zeta potential. Results are reported as the average of at least triplicate sample measurements. Nanoparticles were also made at three different $\mathrm{pH}$ levels to explore how varying $\mathrm{pH}$ may affect particle size and zeta potential. Accelerated exposure studies were conducted using a Wyatt Technology Mobius DLS (Wyatt Technology Co., Goleta, CA, USA) and zeta potential system; measurements were conducted at $25^{\circ} \mathrm{C}, 37^{\circ} \mathrm{C}$, and $60{ }^{\circ} \mathrm{C}$, respectively, for $6 \mathrm{~h}$ per temperature.

\section{Conclusions}

This work describes the thermal properties of water-insoluble $\alpha$-glucans synthesized via glucansucrases and the thermal stability of nanoparticles formed from them. The $\alpha$-glucan nanoparticles have been shown to remain stable over a 7-month period and up to $86^{\circ} \mathrm{C}$. These properties make the $\alpha$-glucan nanoparticles potentially highly stable, long-term controlled-release carriers of hydrophobic bioactives and sensors for analytes like mycotoxins that exhibit environment-dependent modulation of fluorescence.

Author Contributions: Conceptualization, K.O.E., D.L.C. and M.A.; Formal analysis, K.O.E.; Investigation, K.O.E., C.S., D.L.C., R.C., G.L.C. and S.K.; Methodology, K.O.E., C.S., D.L.C., and M.A.; Validation, K.O.E., C.S., D.L.C.; Writing—original draft, K.O.E.; Writing—review \& editing, K.O.E., C.S., D.L.C., R.C., G.L.C., S.K. and M.A. All authors have read and agreed to the published version of the manuscript.

Funding: This research received no external funding.

Acknowledgments: The authors would like to thank Wyatt Technologies for the generous loan of their Mobius instrumentation for the accelerated studies. The authors also are deeply indebted to and would like to thank Suzanne Unser, Leslie Smith, and Jason Adkins for their professional technical assistance. This research was supported by the U.S. Department of Agriculture, Agricultural Research Service.

Conflicts of Interest: The authors declare no conflict of interest. Mention of trade names or commercial products in this publication is solely for the purpose of providing specific information and does not imply recommendation or endorsement by the U.S. Department of Agriculture. USDA is an equal opportunity provider and employer. The U.S. Department of Agriculture (USDA) prohibits discrimination in all its programs and activities on the basis of race, color, national origin, age, disability, and where applicable, sex, marital status, familial status, parental status, religion, sexual orientation, genetic information, political beliefs, reprisal, or because all or part of an individual's income is derived from any public assistance program. (Not all prohibited bases apply to all programs.) Persons with disabilities who require alternative means for communication of program information (Braille, large print, audiotape, etc.) should contact USDA's TARGET Center at (202) 720-2600 (voice and TDD). To file a complaint of discrimination, write to USDA, Director, Office of Civil Rights, 1400 Independence Avenue, SW, Washington, D.C. 20250-9410, or call (800) 795-3272 (voice) or (202) 720-6382 (TDD). USDA is an equal opportunity provider and employer. 


\section{Abbreviations}

$\begin{array}{ll}\mathrm{mPa} & \text { mega Pascal } \\ \mathrm{DPH} & \text { 1,6-diphenyl-1,3,5-hexatriene } \\ \text { DLS } & \text { dynamic light scattering } \\ \text { DSC } & \text { differential scanning calorimetry } \\ \text { ARS } & \text { Agricultural Research Service }\end{array}$

\section{References}

1. Sundar, S.; Kundu, J.; Kundu, S.C. Biopolymeric Nanoparticles. Sci. Technol. Adv. Mater. 2010, 11, 014104. [CrossRef] [PubMed]

2. Luo, Y.-H.; Chang, L.W.; Lin, P. Metal-Based Nanoparticles and the Immune System: Activation, Inflammation, and Potential Applications. Biomed. Res. Int. 2015, 2015, 143720. [CrossRef] [PubMed]

3. Rees, D.A.; Scott, W.E. Polysaccharide conformation. Part VI. Computer model-building for linear and branched pyranoglycans. Correlations with biological function. Preliminary assessment of inter-residue forces in aqueous solution. Further interpretation of optical rotation in terms of chain conformation. J. Chem. Soc. B Phys. Org. 1971, 469-479.

4. Ogawa, K.; Yui, T.; Okamura, K.; Misaki, A. Crystalline Features of Streptococcal (1 $\rightarrow 3)-\alpha$-D-Glucans of Human Saliva. Biosci. Biotechnol. Biochem. 1994, 58, 1326-1327. [CrossRef]

5. Yui, T.; Goto, K.; Kawano, Y.; Ogawa, K. Molecular Modeling Study of Highly Branching (1 $\rightarrow 3)-\alpha-\mathrm{D}-\mathrm{Glucan}$, a Model Polysaccharide for Cariogenic Glucan, Using the N/H Mapping Method. Biosci. Biotechnol. Biochem. 2000, 64, 52-60. [CrossRef] [PubMed]

6. Cote, G.L.; Ahlgren, J.A.; Smith, M.R. Some structural features of an insoluble $\alpha$-D-glucan from a mutant strain of Leuconostoc mesenteroides NRRL B-1355. J. Ind. Microbiol. Biotechnol. 1999, 23, 656-660. [CrossRef]

7. Côté, G.L.; Leathers, T.D. Insoluble glucans from planktonic and biofilm cultures of mutants of Leuconostoc mesenteroides NRRL B-1355. Appl. Microbiol. Biotechnol. 2009, 82, 149-154. [CrossRef]

8. Funane, K.; Ishii, T.; Matsushita, M.; Hori, K.; Mizuno, K.; Takahara, H.; Kitamura, Y.; Kobayashi, M. Water-soluble and water-insoluble glucans produced by Escherichia coli recombinant dextransucrases from Leuconostoc mesenteroides NRRL B-512F. Carbohydr. Res. 2001, 334, 19-25. [CrossRef]

9. Jeon, M.K.; Kwon, T.H.; Park, J.S.; Shin, J.H. In situ viscoelastic properties of insoluble and porous polysaccharide biopolymer dextran produced by Leuconostoc mesenteroides using particle-tracking microrheology. Geomech. Eng. 2017, 12, 849-862. [CrossRef]

10. Seymour, F.R.; Julian, R.L.; Jeanes, A.; Lamberts, B.L. Structural analysis of insoluble d-glucans by fourier-transform, infrared difference-spectrometry: Correlation between structures of dextrans from strains of leuconostoc mesenteroides and of d-glucans from strains of streptococcus mutans. Carbohydr. Res. 1980, 86, 227-246. [CrossRef]

11. Shukla, R.; Shukla, S.; Bivolarski, V.; Iliev, I.; Ivanova, I.; Goyal, A. Structural characterization of insoluble dextran produced by Leuconostoc mesenteroides NRRL B-1149 in the presence of maltose. Food Technol. Biotechnol. 2011, 49, 291-296.

12. Zahnley, J.C.; Smith, M.R. Insoluble glucan formation by Leuconostoc mesenteroides B-1355. Appl. Environ. Microbiol. 1995, 61, 1120-1123. [CrossRef]

13. Wang, Y.; Li, C.; Liu, P.; Ahmed, Z.; Xiao, P.; Bai, X. Physical characterization of exopolysaccharide produced by Lactobacillus plantarum KF5 isolated from Tibet Kefir. Carbohydr. Polym. 2010, 82, 895-903. [CrossRef]

14. Aradmehr, A.; Javanbakht, V. A novel biofilm based on lignocellulosic compounds and chitosan modified with silver nanoparticles with multifunctional properties: Synthesis and characterization. Colloids Surf. A Physicochem. Eng. Asp. 2020, 600, 124952. [CrossRef]

15. Lentz, B.R. Membrane "fluidity" as detected by diphenylhexatriene probes. Chem. Phys. Lipids 1989, 50, 171-190. [CrossRef]

16. Evans, K.O.; Compton, D.L. Phosphatidyl-hydroxytyrosol and phosphatidyl-tyrosol bilayer properties. Chem. Phys. Lipids 2017, 202, 69-76. [CrossRef] [PubMed]

17. Lentz, B.R.; Barenholz, Y.; Thompson, T.E. Fluorescence depolarization studies of phase transitions and fluidity in phospholipid bilayers. 1. Single component phosphatidylcholine liposomes. Biochemistry 1976, 15, 4521-4528. [CrossRef] [PubMed] 
18. Heurtault, B.; Saulnier, P.; Pech, B.; Proust, J.-E.; Benoit, J.-P. Physico-chemical stability of colloidal lipid particles. Biomaterials 2003, 24, 4283-4300. [CrossRef]

19. Jiménez-Sánchez, M.; Pérez-Morales, R.; Goycoolea, F.M.; Mueller, M.; Praznik, W.; Loeppert, R.; Bermúdez-Morales, V.; Zavala-Padilla, G.; Ayala, M.; Olvera, C. Self-assembled high molecular weight inulin nanoparticles: Enzymatic synthesis, physicochemical and biological properties. Carbohydr. Polym. 2019, 215, 160-169. [CrossRef]

20. Šimšíková, M.; Antalík, M.; Kaňuchová, M.; Škvarla, J. Anionic 11-mercaptoundecanoic acid capped ZnO nanoparticles. Appl. Surf. Sci. 2013, 282, 342-347. [CrossRef]

21. McClements, D.J.; Gumus, C.E. Natural emulsifiers-Biosurfactants, phospholipids, biopolymers, and colloidal particles: Molecular and physicochemical basis of functional performance. Adv. Colloid Interface Sci. 2016, 234, 3-26. [CrossRef] [PubMed]

22. Amantea, B.E.; Piazza, R.D.; Chacon, J.R.V.; Santos, C.C.; Costa, T.P.; Rocha, C.O.; Brandt, J.V.; Godoi, D.R.M.; Jafelicci, M.; Marques, R.F.C. Esterification influence in thermosensitive behavior of copolymers PNIPAm-co-PAA and PNVCL-co-PAA in magnetic nanoparticles surface. Colloids Surf. A Physicochem. Eng. Asp. 2019, 575, 18-26. [CrossRef]

23. Côté, G.L.; Skory, C.D. Cloning, expression, and characterization of an insoluble glucan-producing glucansucrase from Leuconostoc mesenteroides NRRL B-1118. Appl. Microbiol. Biotechnol. 2012, 93, 2387-2394. [CrossRef] [PubMed]

24. Cormier, R.; Cote, G.L.; Skory, C.D. Nanoparticles and Films Composed of Water-insoluble Glucan. U.S. Patent 9,708,417, 18 July 2017.

Sample Availability: Samples of the compounds $\alpha$-glucan nanoparticles are available from the authors.

(C) 2020 by the authors. Licensee MDPI, Basel, Switzerland. This article is an open access article distributed under the terms and conditions of the Creative Commons Attribution (CC BY) license (http://creativecommons.org/licenses/by/4.0/). 